\title{
A Social Network Analysis of the Spanish Network of Smart Cities
}

\author{
Ivan Serrano ${ }^{1,2, *} \mathbb{D}$, Laura Calvet-Mir ${ }^{2}{ }^{(0}$, Ramon Ribera-Fumaz ${ }^{2}$, Isabel Díaz ${ }^{2}$ and \\ Hug March 2,3,*iD \\ 1 Estudis de Dret i Ciència Política, Universitat Oberta de Catalunya, Castelldefels, E-08860 Barcelona, Spain \\ 2 Internet Interdisciplinary Institute (IN3), Castelldefels, E-08860 Barcelona, Spain; \\ lcalvetmir@gmail.com (L.C.-M.); rriberaf@uoc.edu (R.R.-F.); twoixa@gmail.com (I.D.) \\ 3 Estudis d'Economia i Empresa, Universitat Oberta de Catalunya, E-08035 Barcelona, Spain \\ * Correspondence: iserranoba@uoc.edu (I.S.); hmarch@uoc.edu (H.M.); Tel.: +34-93-450-5200 (I.S.)
}

Received: 29 May 2020; Accepted: 23 June 2020; Published: 26 June 2020

check for updates

\begin{abstract}
This paper explores the relations of centrality and hierarchy between cities and firms implementing Smart City strategies in the context of the Spanish Network of Smart Cities (RECI). While the literature has usually focused on the global dimension of cities and firms networks, exploring a national case offers interesting insights about the presence of multinational firms in these contexts and the role played by medium-sized cities in their market expansion. The analysis is based on a two-mode network of cities and firms participating in Smart City projects with the usual measures of betweenness, in-degree and closeness, as well as computing the Gini index for each of them to assess the levels of inequality. We then explore whether the structural advantages of participating in these networks have a leveling effect or rather reinforce existing hierarchies of cities. Second, we explore how firms are intertwined in Smart City projects and whether medium-sized local firms have a relevant presence. Our findings suggest these networks become a regional gateway for multinational firms to expand their presence in Smart City national markets, rather than empowering medium-sized cities and small national firms.
\end{abstract}

Keywords: smart cities; Spain; networks; firms

\section{Introduction}

The Smart City has become a key urban paradigm for cities across the world to transform themselves into successful competitive enclaves within the global digital capitalism geographies, through technological transformations. Embedded within the rhetoric of urban competitiveness in a globalized world, the Smart City has become an institutional policy promoted not only by local governments but also by national governments and supranational actors such as the European Union (EU). Moreover, Smart City policies are also presented as a factor of success not only for cities with a prominent role at the world level but also for middle-sized cities often competing in regional rather than global networks [1-3]. Central to this argument is the fact that the development of Smart City projects will enhance the local innovation ecosystems and the creation and/or consolidation of a local smart industry with locally based companies [4]. Yet very often these projects tend to focus on technology rather than the citizens [5]. Critical studies point out that the development of Smart City strategies is part of the neoliberalization of urban governance and instrumental in the colonization of the urban technology markets by transnational corporations [6-9]. In a nutshell, the deployment of Smart City strategies across the globe would reinforce current patterns of uneven development between global and unconnected cities, and between transnational companies and small and medium-sized companies. In contrast, recent critical enquiries on the consolidation of the Smart City have shown that the picture 
is more nuanced [10-12]. A growing literature, based on paradigmatic case studies, has incorporated alternative smart strategies taking into account more inclusive and sustainable possibilities $[13,14]$. Yet, in both cases, Smart City studies need to pay attention to the networked insertion of Smart Cities in the global flows of the digital economy, avoiding "over-territorialization" [15,16]. In other words, move from place-based studies to the relational geographies of the Smart City to explore the limits and potentialities of Smart City models beyond local processes and factors.

In this regard, Wall and Stavrapoulos [15] propose the introduction of network analysis methodologies to understand, among other things, the articulation between local Smart City developments and the global urban and firm dynamics (see, for example, [17]). Following this call for incorporating urban networks analysis, this paper focuses on the articulation between cities, smart strategies and firms. However, rather than focusing on the global level, we will focus on the interrelation between Smart City strategies and national networks, an area that has received little attention so far. Unlike global cities, which usually have the capacity to implement their own agendas, for many regional and provincial cities the capacity to develop Smart City strategies depends on the mediation and support from nation-states or national networks, such as China's or India's Smart City programs. Additionally, the connection of these cities with global flows is often mediated at the national scale by firms that, at the most, establish local offices subordinated to national headquarters (see, for instance, [18] for a good description of the Indian case). Thus, this national mediation can open the door for different Smart City economies not controlled by usual global players.

To contribute to the scholarship documenting the network inequalities of cities and firms in the development of Smart City projects, in this paper we take as case study the Spanish Network of Smart Cities (Red Española de Ciudades Inteligentes), known as RECI, and focus on the relations of centrality and hierarchy among cities and firms in Spain participating of an institutionalized network of Smart Cities. First, we explore whether the structural advantages of participating in these networks have a leveling effect or rather reinforce existing hierarchies of cities. Second, we explore how firms are intertwined in Smart City projects and whether medium-sized local firms have a relevant presence, or whether these networks become a regional gateway for multinational firms to expand their presence, reinforcing their dominance.

Our results suggest that medium-sized cities involved in the network of Smart City projects can have a similar presence to that of bigger cities, but connectedness may come at the price of multinational firms being the main gateway that connect cities to the network. Indeed, our analysis suggests that the network of firms involved in Smart City projects in Spain is dominated by multinational companies. These findings support the claim that Smart City projects at national levels can be regarded as instrumental to the globalization process, by means of which big firms penetrate and maximize their presence in national markets. Moreover, we find limited evidence for a counter-argument often found in the public policy arena, according to which the participation of big firms in national networks, including medium-sized projects and cities, may foster the participation of small national firms that could improve their viability and scale.

\section{Literature Review}

The Smart City paradigm is often optimistically presented as a strategic driver for success in the global network of city competition [19]. With the dominance of information and communication, and technologies as the key strategic vector of economic growth, cities must become "smart", integrating innovative hardware, software and the intensive use of big data and social networks [20]. It can be argued that the rhetoric of the Smart City is the evolution of those positions claiming the need for cities to become competitive agents attracting talent and fostering a creative environment, with economic innovation as the only path towards minimally inclusive societies [21,22]. The "smart" strategy would allow cities not only to compete in a globalized market but also to become more efficient and sustainable, offering economic progress and well-being not only to the more skilled segments of the workforce. 
Indeed, this vision follows the dominant approach in urban studies and globalization. It is argued that cities can be better understood as nodes of a network [23,24]. Instead of classical hierarchical models, Castells [25] defined cities participating in global networks as "spaces of flows". Within contemporary capitalism, the network approach can reinterpret Friedman's definition of cities [26] as basing points of "spatial organization and articulation of production and markets". In the public policy sphere, the metaphor of cities as nodes in a network has resulted in an optimistic expectation about the emergence of Information and Communication Technologies (ICTs) and contemporary globalization taking over the determinant role that "place" had traditionally played in shaping the potential success of cities [21,27]. To do so, cities must cooperate with public and private organizations providing infrastructure and an adequate environment to promote start-ups and attract innovative firms.

In contrast, critical studies highlight that, as a consequence of this dominant Smart City rhetoric, the goal of urban sustainability and economic development becomes the commodification of the city and urban policy $[7,28]$. The existing evidence suggests that being "smart" and integrated into global flows is associated with higher levels of wealth and competitiveness, and to stronger positions in the global network of cities. For instance, Caragliu and Nijkamp [1] find that the intensity of ICT use is correlated with urban wealth, while, in a similar vein, Wall and Stavrapoulos [15] show that GDP levels and the attraction of foreign direct investments are associated to the "smartness" of a city. The intense pursuit of public policies aimed at increasing the competitive capacities of cities might then show that embracing the standardized practices of Smart Cities would not alter existing hierarchies. On the contrary, the consolidation of this paradigm can reinforce the power of big firms instead of balancing the potential of cities, an even deepen the existing inequalities. All in all, big firms are well equipped to succeed in this competitive, innovative and technological paradigm. Cities' and firms' networks reflect the structure of the current process of globalization, but they are fundamental agents of globalization that play a key role in defining which cities become global $[17,29]$. Indeed, the study of city and corporate relations as a dual network has suggested that inequality is greater among cities than among firms, with the former more conditioned by their geographical situation and other classical factors than an optimistic view of ICTs would allow, while the latter more flexible in seeking competitive advantages.

Thus, whether the Smart City epitomizes a deregulated global capitalism, increasing inequalities, commodification, privatization and deregulated and depoliticized public institutions is a matter of controversy. There are critical voices that refer to the Smart City paradigm as an empty concept, reflecting the worldview of the neoliberal project $[6,19,30]$. Under such a dominant market-oriented conception of global networks, cities can become an instrumental device for the intra-national expansion of corporations. From this perspective, cities would have a subordinated role in the configuration of current geographies of globalization, with the Smart City rhetoric permeating urban strategies not only in large but also medium-sized cities.

However, there is limited evidence on how this emerging paradigm affects regional or national networks (see, for instance, [31] for a longitudinal perspective on Smart City networks in China). Research has often focused on global city networks and big firms from advanced business services, and much less on medium-sized and technology-oriented enterprises. Other contributions focus on qualitative case studies or small comparative analyses [32,33], but little has been done on regional networks taking into consideration medium-sized cities and firms. In this sense, the research presented here provides evidence on how cities and firms operate in an institutionalized national network. In doing so, it adds some insights that can be useful to explore the limits and possibilities of the deployment of Smart City strategies to develop local/national smart technologies and economies.

\section{Materials and Methods}

Our case study is the Spanish Network of Smart Cities (RECI), established in June 2012. As mentioned in their mission statement, the network aimed to become "an association of local territories whose entities are representative of the territory and lead innovation systems in their 
own field by promoting their own local network of agents related to research and innovation" [34]. Even though the network was formally promoted by different city council members and currently includes more than 70 cities, it was initially funded by a private foundation (FUNDETEC) sponsored by big national and international firms with a strong presence in Spain, such as INDRA, Hewlett-Packard or Telefónica. Later, in 2015, this foundation was dissolved and the RECI network assumed part of its infrastructure and goals. According to the RECI manifesto, Smart cities are those with "innovation and networking" systems aimed at improving "economic and political efficiency allowing social, cultural and urban development" [34]. From this perspective, the RECI aims to foster a dynamic of cooperation between cities and firms leading to the consolidation of a "Spanish network of smart cities". This policy should promote the automatic and efficient management of urban infrastructure and services, as well as the reduction of public expenditure and the improvement of the quality of services, thus attracting economic activity and generating progress [34]. A key instrument in achieving these goals is "economic growth" by fostering public-private cooperation among cities and creative and technological industries [34].

Many cities have embraced this paradigm as a key strategy that affects different policy areas at the urban level, and the European Union has incorporated the concept in a variety of publicly funded programs for public administrations, research institutions and private companies. Spain's Smart City policy is a good example of a national policy that follows EU's guidelines and other quality standards in the industry (such as the Spanish Agency for Normalization, AENOR), aimed at promoting sustainable growth by fostering the participation of local councils.

\subsection{Methods}

To achieve our research objective we used social network analysis (SNA), a standard tool to study social structures, relations and flows [35]. A growing body of work has applied SNA to understand the relational patterns between firms and cities, mostly at the global/world level $[17,22,36,37]$, but also at the regional [31] and multi-scalar levels [8]. Despite some critiques and limitations of networks as a metaphor to understand relational patterns and the resulting hierarchies in world cities [38-40], SNA has been providing relevant insights for assessing and modeling urban networks through corporate networks [41]. We draw on this body of literature, opting for a two-mode (also known as affiliation) network of cities and firms. This option allows us to explore how both groups of actors are associated to each other by means of Smart City projects in Spain. In this sense, the analysis conducted here expands the available evidence about Smart City networks using SNA to compare cities and firms at a national level, a dimension that has not received attention in the existing literature.

The data on the cities and the corporations involved in urban development through the RECI were compiled through Internet searches of the websites of the RECI, of the city councils, and of news and press releases between July and November 2016. The cities were identified by consulting RECI's official website; at the time of data gathering, the RECI was made up of 65 cities. The firms involved in Smart City projects in these 65 cities were identified through Internet searches of each city's official website (some cities, like Barcelona or Santander, have specific websites for the smart city development projects) and by using key search words such as the cities' names followed by "smart city", "smart city projects" or "urban innovation". Overall, we followed a broad inclusion criterion, searching for corporations that were taking part in Smart City related projects or actions in each city. This strategy resulted in 553 corporations involved in Smart City projects of RECI members, including firms taking part in Smart City actions at a local, regional and international level, for example as part of European consortiums. Of these 553 initially identified firms, 66 were participating in Smart City initiatives in at least two cities of the RECI and were included in the analysis. By doing so, we removed pendant nodes that would be connected to the graph by only one tie. Moreover, these pendant nodes corresponded mostly to cities participating in EU intercity projects, so this decision allowed us to focus on cases actually connected by the RECI association [42], which may help to understand the processes within the RECI at a local level. The number of initial firms was also reduced, as we consider different branches of the 
same firm as a single firm. For example, Acciona Agua, Acciona Energía, Acciona Infraestructuras and Acciona Instalaciones were all considered as Acciona, for clarity purposes. As a result, the final network consisted of 47 cities and 66 firms.

\subsection{The Two-Mode or Affiliation Network of Cities and Corporations}

To assess the firms' articulation in the Smart City development through corporate networks, we constructed a two-mode network or affiliation network. In social network analysis, the term "affiliation" is used to refer to membership or participation data, such as actors participating in events, which consist of a set of binary relationships between members of two sets of items [35]. Examples of affiliation data include corporate board memberships [43,44], attendances of events [45] or patterns of authorships and institutional pathways of scientists [46]. Two-mode networks allowed to capture the interaction among cities and firms and to test an urban network formation hypothesis to deepen the understanding of how individual cities and firms interact locally and form observed corporate networks [41].

We built an affiliation matrix where the rows and the columns correspond to the corporations (a total of 66) and the cities (the 65 cities members of the RECI). The matrix allowed us to determine which corporations participate in which cities' smart projects, and which cities are related to which corporations through Smart City projects. The matrix computes $z_{i j}$ as 1 when a corporation $i$ is present in city $j$, and otherwise as 0 . Moreover, we used Gephi to visualize the bipartite graph resulting from the affiliation network. Links connect firms with cities in which they are involved through Smart City initiatives, and there is no direct linkage within the same set of nodes (i.e., between cities or between firms), which enables a clear visualization of linkages between the two sets. In the visualization of the bipartite graph, the nodes' size represents the betweenness centrality in the network [35]. Two-mode betweenness centrality refers to the number of geodesic paths that pass through a given node, weighted inversely by the total number of equivalent paths between the same two nodes, including those that do not pass through the given node [47]. Accordingly, links between firms always include cities, and links between cities always include firms, which means that cities are on geodesic paths between firms and firms on geodesic paths between cities. A city's betweenness centrality increases when the pairs of firms are linked only through that city, and if a firm is involved in that city, all geodesic paths from that firm must include that particular city. In the same vein, a firm gains betweenness centrality when two cities are only connected between them because of the firm's participation in Smart city projects in those cities. Thus, betweenness centrality is an indicator of a city's (or firm's) strategic power by acting as bridge between firm pairs (or city pairs) that would otherwise be unconnected.

\subsection{Co-Affiliation Networks: Inter-Corporation and Inter-City Linkages}

In order to explore the connections between firms and between cities separately, we transformed the affiliation matrix of corporations and cities $(66 \times 65)$, in which there were no direct linkages within the same set of nodes, into two one-mode squared matrices of overlaps, through the cross-product method for corporations and cities separately [42]. Applied to our binary matrix, each product is 1 only if two corporations were "present" in a city, and the sum across cities yields the number of cities in which the two corporations participated. Then, the first one-mode matrix obtained for corporations $(66 \times 66)$ accounts for the number of cities in which each pair of corporations is present; and the cities $(65 \times 65)$ matrix indicates how many corporations were present in each pair of cities. The co-participation (or co-affiliation) of corporations in Smart City projects of the same city can be considered as an indicator of the extent to which firms get involved in these cities. Then, in this case, co-affiliation would be present if the same firm was involved in Smart City projects in two cities. In other words, the more cities in which two firms co-participate, the greater the possibility that these two firms are somehow "inter-linked" [36]. Because most network methods are designed for the analysis of binary data, we followed the procedures by Neal [36] and Field et al. [48] to dichotomize the resulting valued matrices of overlaps. Inter-firm and inter-city relationships were recoded as present if 
they were two or more. That is, if two corporations have two or more cities in common, the matrix score will be 1 , and 0 if two corporations have less than 2 cities in common. Following the same logic, the inter-city matrix scores were recoded as 1 (present) if two cities had two or more firms in common and 0 otherwise. Setting the threshold of connections at 2 is rather a conservative decision, according to the literature. However, we must be aware of its limitations, particularly when making comparative claims [29]. In order to prevent this overreaching, we tried to emphasize the characterization of the network as a whole while trying to be cautious about its capacity to equalize the structural advantages of cities.

We proceeded by representing the inter-firm and inter-city valued networks, to visualize the most important corporations and cities involved in Smart City projects within the RECI. Subsequently, we computed three normalized measures of centrality degree, closeness and betweenness for each city and firm, the conventional indicators to assess the relative structural position and importance of a node within a network, which in turn creates hierarchies $[17,36,49]$. Following the usual practice in this field, we calculated normalized measures to allow for the comparability between the different measures of centrality. Degree centrality accounts for the number of direct links within a network. In this case, degree centrality refers to the direct links (both incoming and outgoing) between cities or between firms, which indicates the direct involvement in the network. Closeness centrality captures the extent to which a city is directly connected to other cities in the network or separated from them by only short indirect linkages, reflecting the notion that both direct and indirect linkages contribute to a city's centrality and to opportunities for capital accumulation or innovation diffusion [36]. The closer two firms are in the network, the less dependent one is on intermediary channels. Thus, firms with high closeness centrality can provide their producer clients with a more independent and rapid access to information from a wider ranges of sources [36]. Betweenness centrality focuses on the extent to which a city or a firm serves as an intermediary that facilitates the flow of resources for other cities (or other firms) in the network. A strong position in terms of betweenness would reflect a brokering or gatekeeping position, which would provide an actor with a unique ability to monitor and control resource flows, acting as an interlocking agent. Finally, we also calculated the Gini coefficient as a measure of inequality within each of these centrality measures of hierarchies, with values closer to 0 indicating more equality. Under the logic of network analysis suggested by Neal [36], this inequality index complements the rank provided by centrality measures by reflecting structural inequalities among cities and firms.

\section{Results}

The bipartite graph from the RECI's two-mode network (Figure 1) shows to what extent cities and corporations are in structural advantage positions when acting as interlocking agents. Bigger nodes have greater betweenness centrality and function as "brokers" in the network. Spanish firms such as Telefónica, Indra, Acciona or Tecnalia have a strong presence in the network, but foreign capital firms such as Philips or Endesa (which was acquired by the Italian group Enel in 2009) with a relevant position can also be found. Among cities, Madrid, Barcelona, Málaga or the association between Palencia and Valladolid have a strong position within the network. A bipartite graph such as the one represented in Figure 1 offers a general approach to a two-mode network, indicating that some companies seem to play a prominent role and that certain cities-mostly big Spanish agglomerations-seem to act as connecting nodes among firms and the rest of the cities. However, it does not fully reflect the internal features of the network, that is, how their presence is structured.

To further explore the multiple dimensions of a two-mode network, the data informing the visualization offers relevant insights about the characteristics of cities' and firms' participation. For instance, according to the number of cities where each corporation is present (shown in Table S1, in the Supplementary Data section) Telefónica is involved in 17 cities, followed by corporations such as Acciona, Indra or Phillips, which are involved in eight cities. This defines a network structure with a strong presence of major companies of Spanish origin. Conversely, over $65 \%$ of the corporations 
identified were only present in two cities, which indicates that a small number of corporations articulate the core of the Smart City development within the RECI. However, this is not to say multinational companies are absent. It is worth mentioning that multinational companies not based in Spain represent four out of the first 11 companies present in at least five cities. Moreover, when considering the total amount of companies which are at least present in two cities, more than half of them $(54.5 \%)$ are multinational companies with non-Spanish capital, which suggests that the RECI can be seen as a network that facilitates the entrance into the Spanish market, where these companies benefit from a structural advantage by being associated to Spanish firms. This possibility is consistent with the data displayed in Table S4 (Supplementary Material section), where we find that foreign multinationals are present in nine out of the 14 top pairs of companies with a shared presence in the same city.

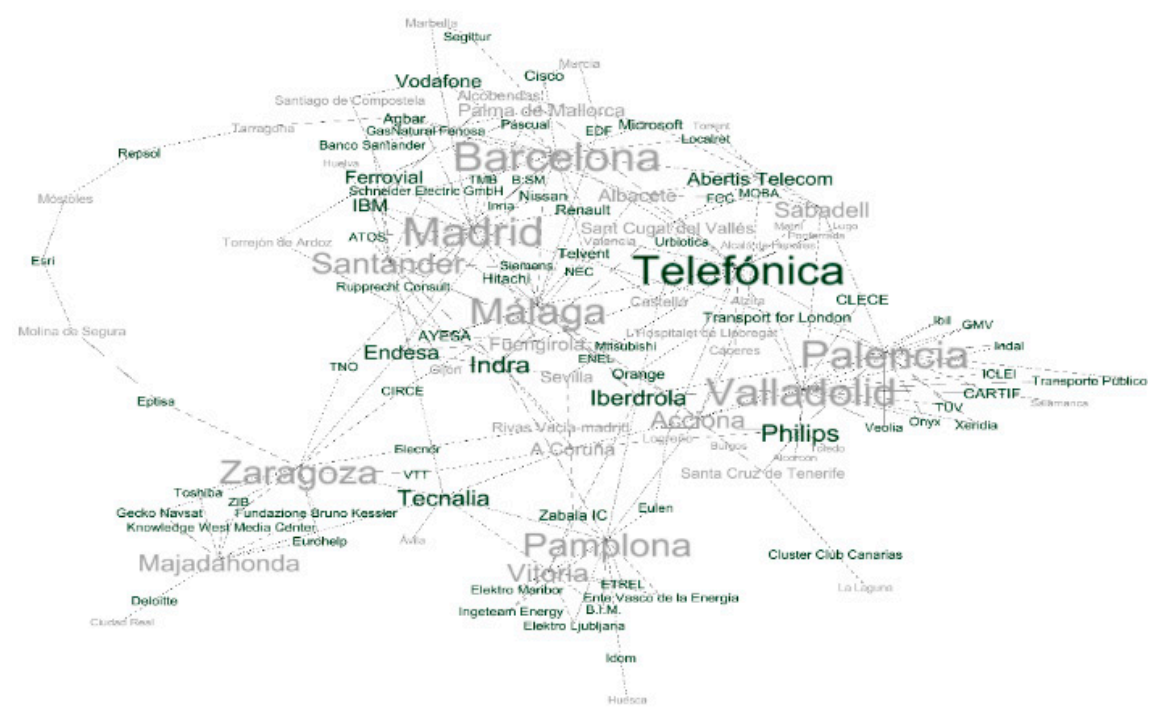

Figure 1. Bipartite graph of the two-mode network city-by-firm of the RECI. Font size represents betweenness centrality. Darker color is used to identify firms, while lighter correspond to cities.

Turning to the cities' presence in the network, we find cities such as Barcelona, Madrid or Valladolid/Palencia, with at least 16 corporations present in two cities of the RECI, taking part in Smart City projects (see Table S2 in the Supplementary Materials). Other important cities in terms of the number of corporations involved are Málaga, with 15, or Pamplona and Santander, with 12 corporations each. A key finding is that a remarkable percentage (29\%) of cities belonging to the network-a total of 19-do not participate in Smart City projects despite being institutional members of the RECI, and 13 other cities have a minimal participation, with only one corporation involved in a Smart City project. In most cases, cities in the network that do not participate correspond to less populated cities, even though there are some cases of relatively populated ones with just one participation or not participating at all, such as Las Palmas or Cordoba, both with a population above 300,000. However, the highest concentration of firms in Smart City projects is found among the most populated cities. There are some relative exceptions, such as Palencia, but this can be considered as a single case, since it is associated with Valladolid in a joint partnership for Smart City projects.

\subsection{The Cities Network}

Cities are mapped in a network graph (Figure 2) with label sizes proportional to their betweenness. Barcelona, Málaga or the association between Palencia and Valladolid appear as the main nodes of the network in terms of their brokering capacity. The graph shows that bigger cities not only have a higher presence of corporations and more connections but also tend to be connected among them. Furthermore, a closer look also suggests that in some cases these cities may have a neighboring effect, playing a leading role for medium-sized cities in their metropolitan areas. 


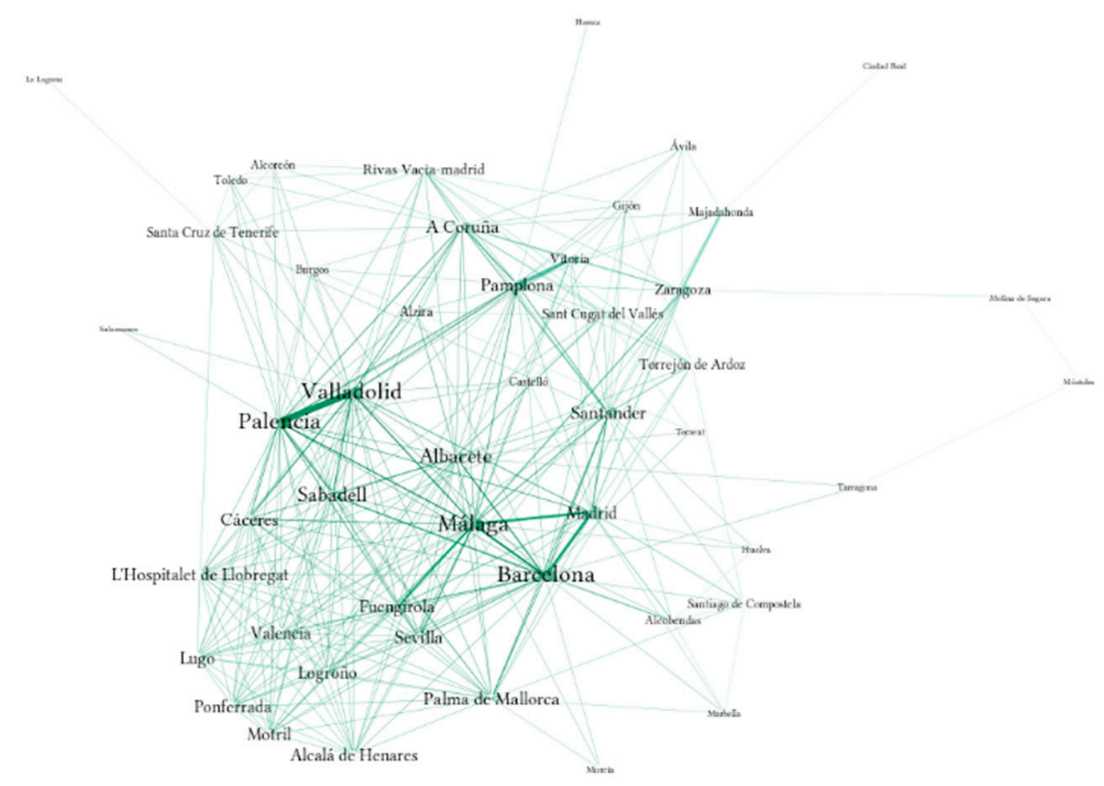

Figure 2. Inter-city networks. Node size is based on betweenness centrality in the network. A tie between nodes means they have at least two corporations in common.

Table S3 displays pairs of cities that share at least three corporations. This threshold allowed us to focus on those cases where participation in the network would provide a structural advantage for cities offering the possibility of a high level of interaction with companies and other cities. The pairs of cities with the highest number of corporations shared are Valladolid and Palencia, which are the capital of neighboring provinces. However, the reason for their close connection is that they established a platform known as Smart City Valladolid and Palencia to foster public-private collaborations for both joint and individual innovations in relation to Smart City development. As for the rest of cities with high numbers of shared corporations, we find different yet complementary situations. On the one hand, big cities such as Madrid, Barcelona or Malaga are usually well connected among them; on the other hand, they could benefit from a neighboring effect, that is, cities from the same region have more options to share the presence of the same firms. This is the case of cities such as Sabadell (near Barcelona) or Fuengirola (near Malaga), but there are opposite situations such as Madrid, which is in general poorly connected to its metropolitan cities. Table S3 in the Supplementary Materials illustrates these possible relations for cities sharing at least three firms. A total of 11 out of 15 pairs include at least one of the main Spanish cities, while eight cases feature some kind of connection, either top-to-top city, regional or metropolitan - variations that would deserve further research combining a quantitative and qualitative analysis and exploring causal factors such as the socioeconomic structure or the political parties in government. However, while factors such as regional and metropolitan links could help explain the cities' connections, it seems that the cities' links seem to follow a hierarchical logic, with bigger cities more often connected among them.

To capture the whole complexity of the data informing the visualization, Table S6 includes individual measures of degree, betweenness and closeness. Moreover, a Gini coefficient is computed for each measure to assess the inequality of the three indicators. These measures reveal two further features of the network as a whole. First, betweenness indicates that even the most successful brokering cities acting as the shortest path between two other cities do not play this role very often: Malaga scores 3.3, followed by Barcelona or Santander, with scores below 3. Accordingly, these cities tend to have low scores of degree and closeness, indicating they are poorly connected to the other cities. Second, although the network is characterized by low centrality levels, there are high disparities among cities, as reflected in the high Gini's coefficient on betweenness (0.88) and degree (0.79), given that most cities never act as brokers between another pair of cities and tend to have few connections to other cities. 
A possible explanation for this situation is that firms may feature higher levels of connectivity and brokering capacity, aspects that we explore in the next subsection.

\subsection{The Firms Network}

In the case of cities, following the same criteria, we have identified pairs of corporations that share their presence in at least three cities (Table S4). Telefónica is the company with more presence in this list, participating in five out of 14 pairs, followed by Endesa, with four pairs. Other companies such as Acciona, Iberdrola or Philips are present in three pairs. Accordingly, these companies are also those with more shared participations in cities, and they are particularly associated with each other. For instance, the pairs Acciona-Iberdrola, Telefónica-Acciona and Telefónica-Endesa all share a presence in four cities. This evidence suggests interesting conclusions about the corporate network of Smart City projects in Spain. On the one hand, most presences in the same city correspond mostly to multinational Spanish capital firms, while foreign capital corporations tend to share their presence in RECI's member cities with a Spanish multinational. It must be noted here that the case of Endesa, which was acquired by the Italian Enel in 2009, could be seen in this sense as a strategy pursued by multinational firms to gain access to new markets by acquiring local companies. Thus, in all cases, most companies are well-established multinational firms, either with Spanish or foreign capital. This would call into question the expectation that Smart City networks would foster the participation of local and medium-to-small companies. On the contrary, big firms seem to enjoy greater structural advantages from the network. On the other hand, this pattern could also indicate that participating in this network offers foreign firms a mediated access to the growing Spanish Smart City market.

The firm network (Figure 3) shows the prominent role of Telefónica and Iberdrola in terms of betweenness, followed by Acciona, Tecnalia, Iberdrola and Endesa. With the exception of Endesa (probably having to do with its acquisition, mentioned above), all correspond to Spanish multinational firms, which is consistent with the idea that they play a key role as gateways for international companies to enter the Spanish market.

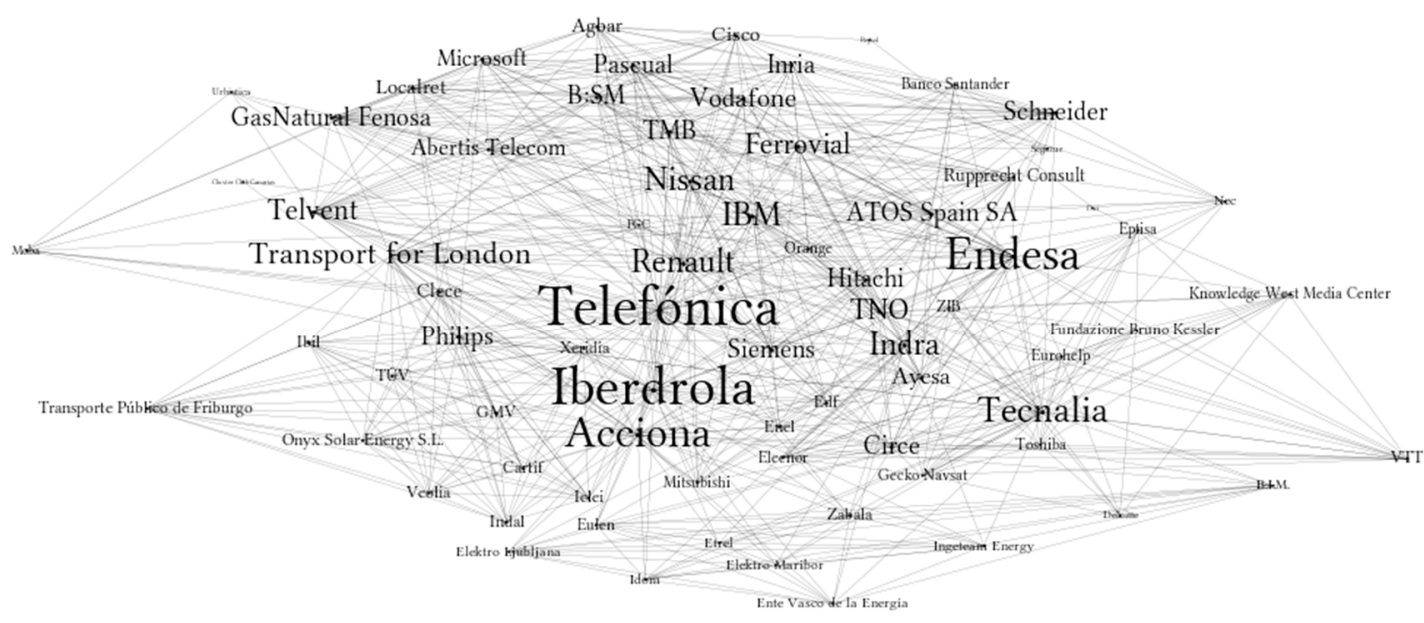

Figure 3. Inter-firm networks. Node size is based on betweenness centrality in the network. A tie between nodes means they have at least two cities in common.

Their capacity for mediation is confirmed when analyzing the specific scores for the main firms in the list, as displayed in Table S5. Telefónica and Iberdrola display higher measures not only in betweenness but also in the other two measures of centrality (in-degree and closeness), confirming their prominent role as fundamental nodes in the network. The other corporations appear in different positions for each centrality measure. Acciona and Endesa have similar in-degree scores, but Endesa appears before Acciona with regard to closeness. Tecnalia, for example, has more betweenness than Endesa. These variations suggest that, in terms of hierarchies, there are remarkable levels of inequality, 
and the Gini score of betweenness confirms that a small set of companies concentrate most of the intermediary role.

Thus, the firm network offers two interesting conclusions. Some companies combine a relatively high level of connections with a low brokering capacity. We find this situation in multinational companies such as Philips, which could suggest that participating in the network is a way of accessing the Spanish Smart City market. As the participation of multinational companies is mediated by local multinational firms, this presence does not provide them with a brokering capacity. Conversely, some companies have relatively low levels of connections but a relevant betweenness capacity, suggesting that they act as strategic hubs in the network because of their specialization (like Tecnalia, a technological corporation mostly focused on applied research) and even regardless of their origins, if they have been established in Spain for a long period of time (the case of IBM).

\section{Discussion}

The network analysis carried out for the Spanish Network of Smart-Cities (RECI) indicates that the latter is not able to involve a significant amount of its members. A high percentage of member cities only participate in a single Smart City project or in no project at all. The centrality measures computed in the analysis show a network characterized by a combination of low centrality scores and a high level of inequality. Only a handful of cities are able to have a brokering role, but they very rarely find themselves in this situation. As for the degree measures, complemented with the overall Gini index, we obtained a picture where inequality is indeed a key feature of the city network. Therefore, the data revealed that a small number of cities concentrate most of the connections, well above the other member cities. Moreover, they mostly correspond to Spain's larger cities, such as Madrid, Barcelona or Malaga, suggesting that cities that are already more powerful obtain better structural advantages from participating in the network. Thus, the network actually reinforces the existing hierarchies of cities, instead of leveling the field for medium-sized cities.

Concerning the role of companies, the core of Smart City development within the RECI network consists of a small number of corporations, with Spanish-capital multinational firms having the strongest presence. They represent key economic sectors with a strong technological component, from telecommunications (Telefónica and Abertis) to energy (Iberdrola and Endesa) and urban services and infrastructure (Acciona and Ferrovial). In this sense, the Spanish ecosystem of Smart City projects seems an opportunity to reinforce national companies, but only those with a strong international dimension. These elements are reflected by the Gini coefficient, with a small number of companies benefiting from the structural advantages of the network. This indicates that structural advantages are more available to the biggest companies, while medium-sized and national companies seem to have a poorer access to the network's possibilities. Moreover, the brokering role of bigger national companies seems to act as a hub for non-Spanish multinationals to gain access to the national market. Rather than having links with other non-Spanish firms, they tend to be related mostly with Spanish multinationals. Thus, the high proportion of international firms that are present in at least two cities reinforces the claim that participating in RECI's member cities is a way of accessing Spain's growing Smart City market, which, according to specialized reports, can reach billions of euros in the next years.

Thus, firms seem to benefit more from the network than cities, even though the original goal of the RECI is to strengthen cities' capabilities. In fact, this kind of institutionalized networks seems to strengthen a small group of cities and companies enjoying greater structural advantages, reinforcing the concentration dynamic and increasing the inequalities in the development of Smart Cities in Spain. As for non-central actors, neither medium-sized cities nor Spanish capital firms seem to obtain the same benefits from participating in the network, the exception being foreign-capital firms that may see an opportunity to access an emerging regional market. These contradictory outcomes show the necessity to move beyond discursive analysis based on the acceptance or rejection of the rhetoric underpinning Smart City discourse, based on market notions such as competitiveness, survival and efficiency. In order to understand how more progressive, inclusive and sustainable smart strategies can be deployed, 
it is necessary to explore the geographical relationalities in which the actually existing Smart City is produced [50] and, more particularly, the necessity to link place-based dynamics with supra-local network developments [15]. To sum up, this evidence has implications for the design and evaluation of actions aimed at developing Smart City initiatives. Our findings point to the necessity of establishing clear goals and indicators of evaluation when adopting Smart City initiatives. Otherwise, unexpected outcomes may arise which are actually detrimental to the formal objectives of the institutional policy.

\section{Conclusions}

Institutionalized Smart City initiatives are aimed at delivering better structural advantages to cities [1]. It is argued that, in the context of an increasingly competitive globalized world, the Smart City model in its mainstream formulation can deliver a better city governance, taking advantage of the ICT possibilities developed by means of public-private partnerships [51,52]. In national contexts such as our case study, in Spain, institutionalized networks are expected to be particularly beneficial to medium-sized cities and firms. However, from a more critical perspective, it could be argued that the expansion of the Smart City paradigm in national arenas can become a gateway for bigger firms to expand their market possibilities, without changing the hierarchy of cities, if not reinforcing existing inequalities [53-55].

This paper has explored the relations of centrality and hierarchy between cities and firms implementing Smart City strategies in the context of the Spanish Network of Smart Cities (RECI) as of 2018. Since the literature has usually focused on the global dimension of cities and firms networks [15], exploring a national case offers interesting insights about the presence of multinational firms in these contexts and the role played by medium-sized cities in their market expansion. Building on a two-mode network of cities and firms participating in Smart City projects, we have explored whether the structural advantages from participating in these networks have a leveling effect or rather reinforce existing hierarchies of cities. We have also analyzed how national and multinational corporations are interrelated in Smart City projects and whether medium-sized local companies have a relevant presence or not. Our findings suggest that these networks become a regional gateway for multinational firms to expand their presence in Smart City national markets, rather than empowering medium-sized cities and small national firms. Thus, our results suggest that an institutionalized network in a national context can indeed reflect the existing hierarchy of cities, while acting as a gateway for foreign multinational companies to have an emerging access to a growing market, rather than providing better structural advantages to medium-sized cities and local companies.

These elements should be taken into consideration when designing and implementing institutionalized policies on Smart cities, taking into account that national Smart City policies (with specific objectives such as promoting Smart City industry clusters) may not be fully aligned with local Smart City strategies (centered on implementing the best solutions available). While it might be difficult to reconcile the multiple rationalities behind the promotion of Smart City initiatives, instruments such as networks of cities may help to reconcile both perspectives, if their functioning is carefully analyzed and there is the clear objective of preserving public interests over private ones.

Supplementary Materials: The following are available online at http://www.mdpi.com/2071-1050/12/12/5219/s1, Table S1, Corporations identified as participating in smart city projects in cities member of the RECI by the number of cities in which they are involved; Table S2, RECI city members by the number of corporations identified as participating in smart cities initiatives that were present in at least 2 cities of the network; Table S3, Pairs of cities that shared at least three corporations involved in smart city projects; Table S4, Pairs of corporations that shared participation in three or more cities; Table S5, Centrality and hierarchy in the RECI corporate networks; Table S6, Centrality and hierarchy in the RECI city network.

Author Contributions: Conceptualization, I.S., R.R.-F., H.M. and L.C.-M.; methodology; I.S. and L.C.-M.; formal analysis; I.S. and L.C.-M.; investigation, I.S.; data curation, I.D., I.S. and L.C.-M.; writing-original draft preparation, I.S.; writing-review and editing; I.S., R.R.-F., H.M. and L.C.-M.; visualization, I.S. All authors have read and agreed to the published version of the manuscript.

Funding: The authors wants to express their gratitude for the internal funding of the Internet Interdisciplinary Institute (IN3)-Universitat Oberta de Catalunya (UOC) that contributed to develop this project. 
Conflicts of Interest: The authors declare no conflict of interest.

\section{References}

1. Caragliu, C.; Nijkamp, P. Smart Cities in Europe. J. Urban Technol. 2011, 18, 65-82. [CrossRef]

2. Lopes, I.M.; Oliveira, P. Can a small city be considered a smart city? Procedia Comput. Sci. 2017, 121, 617-624. [CrossRef]

3. Kollar, M.; Bubbico, R.L.; Arsalide, N. Smart Cities, Smart Investment in Central, Eastern and South-Eastern Europe. Economics—Thematic Studies; European Invesment Bank: Kirchberg, Luxemburg, 2018.

4. Almirall, E.; Wareham, J.; Ratti, C.; Conesa, P.; Bria, F.; Gaviria, A.; Edmondson, A. Smart Cities at the Crossroads. Calif. Manag. Rev. 2016, 59, 141-152. [CrossRef]

5. Neirotti, P.; De Marco, A.; Cagliano, A.C.; Mangano, G.; Scorrano, F. Current trends in Smart City initiatives: Some stylised facts. Cities 2014, 38, 25-36. [CrossRef]

6. Hollands, R.G. Will the real smart city please stand up? Intelligent, progressive or entrepreneurial? City 2008, 12, 303-320. [CrossRef]

7. Hollands, R.G. Critical interventions into the corporate smart city. Camb. J. Reg. Econ. Soc. 2014, 8, 61-77. [CrossRef]

8. Martinus, K.; Sigler, T.; Searle, G.; Tonts, M. Strategic globalizing centers and sub-network geometries: A social network analysis of multi-scalar energy networks. Geoforum 2015, 64, 78-89. [CrossRef]

9. Datta, A. New urban utopias of postcolonial India. Dialog. Hum. Geogr. 2015, 5, 3-22. [CrossRef]

10. Grossi, G.; Pianezzi, D. Smart cities: Utopia or neoliberal ideology? Cities 2017, 69, 79-85. [CrossRef]

11. Mora, L.; Bolici, R.; Deakin, M. The First Two Decades of Smart-City Research: A Bibliometric Analysis. J. Urban Technol. 2017, 24, 3-27. [CrossRef]

12. Mora, L.; Deakin, M.; Reid, A.; Angelidou, M. How to Overcome the Dichotomous Nature of Smart City Research: Proposed Methodology and Results of a Pilot Study. J. Urban Technol. 2018, 26, 89-128. [CrossRef]

13. Cardullo, P.; Cesare, F.; Kitchin, R. The Rigth to the Smart City; Emerald Group Publishing: Bingley, UK, 2019.

14. March, H.; Ribera-Fumaz, R. Barcelona: From corporate smart city to technological sovereignty. In Inside Smart Cities: Place, Politics and Urban Innovation; Karvonen, A., Caprotti, F., Cugurullo, F., Eds.; Routledge: Abingdon, UK, 2018; pp. 227-242.

15. Wall, R.; Stavropoulos, S. Smart cities within world city networks. Appl. Econ. Lett. 2016, 23, 1-5. [CrossRef]

16. Charnock, G.; March, H.; Ribera-Fumaz, R. From smart to rebel city? Worlding, provincialising and the Barcelona Model. Urban Stud. 2019, 0042098019872119. [CrossRef]

17. Alderson, A.S.; Beckfield, J. Power and Position in the World City System. Am. J. Sociol. 2004, 109, 811-851. [CrossRef]

18. Praharaj, S.; Han, J.H.; Hawken, S. Urban innovation through policy integration: Critical perspectives from 100 smart cities mission in India. City Cult. Soc. 2018, 12, 35-43. [CrossRef]

19. Söderström, O.; Paasche, T.; Klauser, F. Smart cities as corporate storytelling. City 2014, 18, 307-320. [CrossRef]

20. Kitchin, R. Big Data, new epistemologies and paradigm shifts. Big Data Soc. 2014, 1, 2053951714528481. [CrossRef]

21. Florida, R. The Rise of the Creative Class—Revisited: Revised and Expanded; Basic Books (AZ): New York, NY, USA, 2014.

22. Krätke, S. Global Pharmaceutical and Biotechnology Firms' Linkages in the World City Network. Urban Stud. 2013, 51, 1196-1213. [CrossRef]

23. Sassen, S. Locating cities on global circuits. Environ. Urban. 2002, 14, 13-30. [CrossRef]

24. Sassen, S. Global Networks, Linked Cities; Routledge: London, UK, 2002.

25. Castells, M. The Rise of the Network Society; Blackwell: Malden, MA, USA, 1996.

26. Friedmann, J. The world city hypothesis. Dev. Chang. 1986, 17, 69-83. [CrossRef]

27. Mitchell, W.J. City of Bits: Space, Place, and the Infobahn; MIT Press: Cambridge, MA, USA, 1996.

28. March, H.; Ribera-Fumaz, R. Smart contradictions: The politics of making Barcelona a Self-sufficient city. Eur. Urban Reg. Stud. 2016, 23, 816-830. [CrossRef]

29. Neal, Z.P. Well connected compared to what? Rethinking frames of reference in world city network research. Environ. Plan. A Econ. Space 2016, 49, 2859-2877. [CrossRef] 
30. Coppola, A.; Vanolo, A. Normalising autonomous spaces: Ongoing transformations in Christiania, Copenhagen. Urban Stud. 2014, 52, 1152-1168. [CrossRef]

31. Lu, D.; Tian, Y.; Liu, Y.; Zhang, Y. The Performance of the Smart Cities in China-A Comparative Study by Means of Self-Organizing Maps and Social Networks Analysis. Sustainability 2015, 7, 7604-7621. [CrossRef]

32. Bakıc1, T.; Almirall, E.; Wareham, J. A Smart City Initiative: The Case of Barcelona. J. Knowl. Econ. 2012, 4, 135-148. [CrossRef]

33. Anthopoulos, L. Smart utopia VS smart reality: Learning by experience from 10 smart city cases. Cities 2017, 63, 128-148. [CrossRef]

34. Red Española de Ciudades Inteligentes. Available online: http://reddeciudadesinteligentes.es/ (accessed on 19 June 2020).

35. Borgatti, S.P.; Halgin, D.S. Analyzing affiliation networks. Sage Handb. Soc. Netw. Anal. 2011, 1, 417-433.

36. Neal, Z.P. The duality of world cities and firms: Comparing networks, hierarchies, and inequalities in the global economy. Glob. Netw. 2007, 8, 94-115. [CrossRef]

37. Hennemann, S.; Derudder, B. An Alternative Approach to the Calculation and Analysis of Connectivity in the World City Network. Environ. Plan. B Plan. Des. 2014, 41, 392-412. [CrossRef]

38. Robinson, J. Cities in a World of Cities: The Comparative Gesture. Int. J. Urban Reg. Res. 2010, 35, 1-23. [CrossRef]

39. Robinson, J. Global and world cities: A view from off the map. Int. J. Urban Reg. Res. 2002, 26, 531-554. [CrossRef]

40. Smith, R.; Doel, M.A. Questioning the Theoretical Basis of Current Global-City Research: Structures, Networks and Actor-Networks. Int. J. Urban Reg. Res. 2010, 35, 24-39. [CrossRef]

41. Derudder, B.; Taylor, P.J.; Hoyler, M.; Ni, P.; Liu, X.; Zhao, M.; Shen, W.; Witlox, F. Measurement and interpretation of connectivity of Chinese cities in world city network, 2010. Chin. Geogr. Sci. 2013, 23, 261-273. [CrossRef]

42. Hanneman, R.A.; Riddle, M. Introduction to Social Network Methods; University of California Riverside: Riverside, CA, USA, 2005.

43. Lester, R.H.; Cannella, A.A. Interorganizational Familiness: How Family Firms Use Interlocking Directorates to Build Community-Level Social Capital. Entrep. Theory Pract. 2006, 30, 755-775. [CrossRef]

44. Robins, G.; Alexander, M. Small Worlds among Interlocking Directors: Network Structure and Distance in Bipartite Graphs. Comput. Math. Organ. Theory 2004, 10, 69-94. [CrossRef]

45. Jones, L.W.; Davis, A.; Gardner, B.B.; Gardner, M.R. Deep South: A Social Anthropological Study of Caste and Class. South. Econ. J. 1942, 9, 159. [CrossRef]

46. Corbera, E.; Calvet-Mir, L.; Hughes, H.; Paterson, M. Patterns of authorship in the IPCC Working Group III report. Nat. Clim. Chang. 2015, 6, 94-99. [CrossRef]

47. Borgatti, S.P.; Everett, M.G.; Johnson, J.C. Analyzing Social Networks; Sage: London, UK, 2018; ISBN 978-1-5264-1848-7.

48. Field, S.; Frank, K.A.; Schiller, K.; Riegle-Crumb, C.; Muller, C. Identifying positions from affiliation networks: Preserving the duality of people and events. Soc. Netw. 2006, 28, 97-123. [CrossRef]

49. Wall, R.; Van Der Knaap, G.A. Sectoral Differentiation and Network Structure Within Contemporary Worldwide Corporate Networks. Econ. Geogr. 2011, 87, 267-308. [CrossRef]

50. Shelton, T.; Zook, M.; Wiig, A. The 'actually existing smart city'. Camb. J. Reg. Econ. Soc. 2014, 8, 13-25. [CrossRef]

51. Bank, T.W.; Group, W.B. World Development Report 2016: Digital Dividends; World Bank Publications: Washington, DC, USA, 2016.

52. Habitat, U.N. World Cities Report 2016: Urbanization and Development_Emerging Futures; UN-Habitat: Nairobi, Kenya, 2016.

53. Mosco, V. The Smart City in a Digital World; Emerald Publishing: Bingley, UK, 2019.

54. Clark, J. Uneven Innovation: The Work of Smart Cities; Columbia University Press: New York, NY, USA, 2020.

55. Walker, R.A. Pictures of a Gone City: Tech. and the Dark Side of Prosperity in the San Francisco Bay Area; PM Press: Oakland, CA, USA, 2018.

(C) 2020 by the authors. Licensee MDPI, Basel, Switzerland. This article is an open access article distributed under the terms and conditions of the Creative Commons Attribution (CC BY) license (http://creativecommons.org/licenses/by/4.0/). 